\title{
Gastrointestinal Bleeding in Children can have Many Causes
}

\author{
Sur Genel ${ }^{1,2 *}$, Sur M Lucia1, Sur G Daniel ${ }^{1}$ and Floca Emanuela ${ }^{1}$
}

${ }^{1}$ University of Medicine and Pharmacy, IuliuHatieganu, Cluj-Napoca, Romania

${ }^{2}$ Emergency Clinical Hospital for Children, Cluj-Napoca, Romania

\begin{abstract}
Acute gastrointestinal bleeding in children is a common emergency. Gastrointestinal bleeding may involve any part of the digestive tract from mouth to anus. Causes of gastrointestinal bleeding in children are multiple and can be grouped according to the involved portion of the digestive tract and age.
\end{abstract}

Keywords: Children; Gastrointestinal; Hemorrhage

\section{Background}

Acute gastrointestinal bleeding is a common emergency. The digestive hemorrhage in infant and children is a common problem accounting for $10 \%-20 \%$ of referrals to pediatric. The etiology comprises extra digestive disease (coagulopathies, portal hypertension) and digestive disease (infections, malformations, inflammation) [1]. The treatment depends on the quantity of the blood loss, on the necessary drugs with etiopathogenetic impact. For all patients with significant gastrointestinal bleeding is required to place an intravenous access to ensure patient stability, to initiate fluid and blood resuscitation, to establish adequate oxygen delivery and to correct coagulopathies. The digestive endoscopy has an important role in diagnostic and sometimes it is a therapeutic method $[2,3]$.

\section{Epidemiology}

Severe gastrointestinal bleeding is rare in the general pediatric population. Upper gastrointestinal bleeding comprises 6\%-20\% in pediatric population [1]. The incidence of lower gastrointestinal bleeding has not been well established. Gastrointestinal bleeding in hospitalized children in USA was $23.38 \%$. The highest incidence of gastrointestinal bleeding was manifested by blood in stool (17.6 per 10000) followed by hematemesis (11.2 per 10000). The highest mortality rates associated with gastrointestinal bleeding were observed in cases with intestinal perforation $(8.7 \%)$ and esophageal perforation $(8.4 \%)[2]$

\section{Etiology}

The causes of gastrointestinal bleeding can be categorized according to age groups: neonates, children aged 1 month -1 year, $1-2$ years, and older than 2 years [3].

Neonates -Anal fissure is the most common cause of gastrointestinal bleeding in infant. The cause is a tear at the mucocutaneous line located especially in the midline. Other causes include bacterial enteritis, milk protein allergy, swallowed maternal blood, intussusception, and lymphonodular hyperplasia [4,5]. Food allergies are immunologically mediated adverse reactions to foods. Eggs, milk, peanuts, soy, fish, shellfish, tree nuts, and wheat are foods most often implicated. Erosion of the gastric, duodenal and esophageal mucosa is frequent cause for neonatal gastrointestinal bleeding. The erosions of mucosa are caused by dramatic increase in gastric acid secretion and the laxity of gastric sphincter. Maternal stress in the third trimester can induce infantile peptic ulcer. Many drugs are implicated in neonatal gastrointestinal bleeding. Drugs such as NSAID, cortisone, heparin, indomethacin, aspirin, cephalotin, and phenobarbital cause coagulation abnormalities in neonates [6]. Prematurity, mechanical ventilation, and neonatal distress are all associated with stress gastritis. Other causes of gastrointestinal bleeding in neonates are volvulus, coagulopathies, arteriovenous malformation, necrotizing enterocolitis, Hirschprung malady, Meckel diverticulum. One of the causes of gastrointestinal bleeding in neonate is hemorrhagic disease of newborn resulting from a deficiency in vit $\mathrm{K}$ - dependent coagulation factors [7-9].

The causes of upper gastrointestinal bleeding in children aged 1 month to 1 year are following: peptic esophagitis, primary gastritis often associated with Helicobacter pylori, steroidal and nonsteroidal antiinflammatory drugs, Zollinger Ellison syndrome, Chron disease, and secondary gastritis in association with systemic illnesses by mucosal ischemia, diffuse erosion, and hemorrhagic gastric mucosa $[3,10]$.

We mentiona the following causes of lower gastrointestinal bleeding in children aged 1month to 1 year: anal fissure located dorsally in the midline, gangrenous bowel in malrotation with volvulus, andhernia with strangulation $[3,11]$.

Upper gastrointestinal bleeding in children aged 1 year to 2 years: Peptic ulcer disease is the most common cause of hematemesis. Peptic ulcer etiologies include NSAID and gastritis causes. Helicobacter pylori are one of the causes of peptic ulcer. Most of the peptic ulcers are secondary to other systemic diseases such as head trauma (Cushing ulcer), burns (Curling ulcer), malignancy or sepsis.

The causes of lower gastrointestinal bleeding in children aged 1 year to 2 years include juvenilepolyps located throughout the colon, Meckel diverticulum, and ectopic gastric mucosa in diverticulum causing ileal ulceration $[8,11]$.

Upper gastrointestinal disease bleeding in children older than 2 years: An important causeog gastrointestinal bleeding is esophageal varices that can result from portal hypertension. One of the most common causes of portal hypertension is portal vein thrombosis. But the most common causes of upper gastrointestinal bleeding in children older than 12 years are: esophagitis, duodenal ulcers, gastritis, Mallory Weiss syndrome $[7,12]$.

${ }^{*}$ Corresponding author: Sur Genel, University of Medicine and Pharmacy, luliu Hatieganu, Cluj-Napoca, Romania, Tel: 0040724504964; E-mail: surgenel@yahoo.com

Received January 01, 2016; Accepted January 02, 2016; Published January 05, 2016

Citation: Genel S, Lucia SM, Daniel SG, Emanuela F (2016) Gastrointestinal Bleeding in Children can have Many Causes. Pharm Anal Acta 7: e184 doi:10.4172/21532435.1000e184

Copyright: $\odot 2016$ Genel S, et al. This is an open-access article distributed under the terms of the Creative Commons Attribution License, which permits unrestricted use, distribution, and reproduction in any medium, provided the original author and source are credited. 
Citation: Genel S, Lucia SM, Daniel SG, Emanuela F (2016) Gastrointestinal Bleeding in Children can have Many Causes. Pharm Anal Acta 7: e184. doi:10.4172/21532435.1000e184

Page 2 of 2

Lower gastrointestinal bleeding in children older than 12 years can appears in juvenile polyps, inflammatory bowel disease (IBD). The diagnosis of inflammatory bowel disease would be well established before the onset of an acute or chronic bleeding. Infections caused by Escherichia coli, Shigella, Clostridium difficile can also be manifested by the emission of blood in the stool. Another causes of lower gastrointestinal bleeding are vascular lesions such as haemangioma, arteriovenous malformations, and vasculitis $[3,13]$.

\section{References}

1. Rotondano G (2014) Epidemiology and diagnosis of acute nonvariceal upper gastrointestinal bleeding. Gastroenterol Clin North Am 43: 643-663

2. Pant C, Sankararaman S, Deshpande A, Olyaee M, Anderson MP, et al (2014) Gastrointestinal bleeding in hospitalized children in the United States. Curr Med Res Opin 30: 1065-1069.

3. Gralnek IM, Dumonceau JM, Kuipers EJ, Lanas A, Sanders DS, et al. (2015) Diagnosis and management of nonvariceal upper gastrointestinal hemorrhage: European Society of Gastrointestinal Endoscopy (ESGE) Guideline. Endoscopy 47

4. Reveiz L, Guerrero-Lozano R, Camacho A, Yara L, Mosquera PA (2010) Stress ulcer, gastritis, and gastrointestinal bleeding prophylaxis in critically ill pediatric patients: A systematic review. Pediatric Critical Care Medicine 11: 124-132.
5. Koletzko S, Jones NL, Goodman KJ, Gold B, Rowland M, et al. (2011) Evidencebased Guidelines From ESPGHAN and NASPGHAN for Helicobacter pylori Infection in Children. J Pediatr Gastroenterol Nutr 53: 230-243.

6. Owensby S, Taylor K, Wilkins T (2015) Diagnosis and management of upper gastrointestinal bleeding in children. J Am Board Fam Med 28: 134-145.

7. Dworzynski K, Pollit V, Kelsey A, Higgins B, Palmer K, et al. (2012) Management of acute upper gastrointestinal bleeding: summary of NICE guidance. BMJ 13: 344 .

8. Greenspoon J, Barkun A (2010) A summary of recent recommendations on the management of patients with nonvariceal upper gastrointestinal bleeding. Pol Arch Med Wewn 120: 341-346.

9. Laine L, Jensen DM (2012) Management of patients with ulcer bleeding. Am J Gastroenterol 107: 345-360.

10. Garcia-Tsao G, Bosch J (2010) Management of Varices and Variceal Hemorrhage in Cirrhosis. N Engl J Med 362: 823-832.

11. Benchimol El, Fortinsky KJ, Gozdyra P, Van den Heuvel M, Van Limbergen J, et al. (2010) Epidemiology of pediatric inflammatory bowel disease: A systematic review of international trends. Inflamm Bowel Dis 17: 423-439.

12. De Greef E, Hauser B, Devreker T, Veereman-Wauters G, Vandenplas $Y$ (2012) Diagnosis and management of cow's milk protein allergy in infants. World J Pediatr 8: 19-24.

13. Sur G, Sur ML, Floca E (2015) Diagnostic Difficulties in Cow's Milk Protein Allergy. Pharm Anal Acta 6:12. 